Int. J. of Modelling, Identification and Control

Copyright (c) 201X Inderscience Enterprises Ltd. 


\title{
The Simulink Implementation of a MPPT technique and control system for a Variable Speed Wind Turbine PMSG
}

\section{Najmeh Rezaei}

School of Electronic Engineering and Computer Science, Queen Mary University of London, London, UK

E-mail: n.rezaei@qmul.ac.uk

\section{Kamyar Mehran}

School of Electronic Engineering and Computer Science, Queen Mary University of London, London, UK

E-mail: k.mehran@qmul.ac.uk

\section{Calum Cossar}

School of Engineering, University of Glasgow, Glasgow, UK

E-mail: Calum.Cossar@glasgow.ac.uk.

\begin{abstract}
An optimal control system is proposed for a wind energy conversion system (WECS) using a direct driven permanent magnet synchronous generator (D-PMSG) connected to the grid via a back-to-back PWM converter with a switching frequency of $10 \mathrm{KHz}$. A maximum power point tracking (MPPT) algorithm used to ensure the maximum power capture from a wind turbine and a PI controller is designed for the wind turbine to generate optimum speed for the generator via an aerodynamic model. The proposed simulation model is developed based on the practical setup parameters to accurately mimic the behaviour of the whole system in MATLAB/Simulink.
\end{abstract}

Keywords: MPPT; PI controller; PMSG; Simulink; WECS; Wind turbine.

\section{Biographical notes:}

Najmeh Rezaei is a researcher with School of Electronic Engineering and Computer Science at Queen Mary University of London. She received her master degrees in electronic engineering from University of Pavia and Polytechnic University of Turin in Italy. Her research interests include projects related to control of motors and converters in power electronics applications and renewable energy systems. She is an author of several international journals, conference proceedings as well as a book chapter.

Calum Cossar was born in Hamilton, Scotland in 1962 and gained a first class BSc (hons) degree in Electronics and Electrical Engineering from the University of Glasgow in 1983. From 1983 to 1988 he worked as a development engineer with Ferranti plc in Edinburgh and then moved back to the University of Glasgow in 1988 to take up a Research Assistant post in the SPEED Laboratory under the guidance of Professor Tim Miller. He was made a permanent Research Technologist in 1991 and subsequently Manager of the SPEED Lab where he was involved in over 20 industrial and government funded projects primarily investigating the control of electric motors and generators including switched reluctance and permanent magnet machines. He is co-author in over 50 publications and currently teaches Electrical Power related courses at the University of Glasgow.

Kamyar Mehran is a lecturer in Power Engineering at Queen Mary University of London, UK. His prior academic posts include research fellow at University of Warwick, UK (2013-2015), and research associate and commercialization manager at Newcastle University and Imperial College London (2010-2013). He completed his PhD degree at Newcastle University, UK in 2009 in Machines, Drives and Control Laboratory. Prior to his $\mathrm{PhD}$, he collected over 8 years of professional experience in ICT and energy industries. His research interests include control of energy storages (grid, vehicular), highswitching power electronic converters and DC microgrids. He is active in the field of intelligent control, fuzzy systems, multi-sensory data fusion over wireless sensor networks with numerous peer-reviewed journal publications and book chapters. 


\section{Introduction}

Wind energy is a renewable energy source that its industry is still in infancy but due to the mandate of Paris climate agreement in 2015, the development of wind turbine generation systems (WTGS) technology has been recently accelerated worldwide. In comparison with other renewable generation systems, WTGS have lower overall economic costs and capacity ratings and the downward trend in its costs is expected to continue (Muyee S. M., 2012). To maximise wind energy utilisation, variable speed constant frequency (VSCF) wind energy conversion systems (WECS) have been widely adopted from the late 1990s (Zhu Y. et al., 2012). We have also witnessed a rapid development of the direct-driven wind turbine (WT) with a permanent magnet synchronous generator (PMSG) in the commercial power industry mainly due to its simple structure, low cost of maintenance, no gearbox requirement, high conversion efficiency and high reliability (Polinder H. et al., 2006).

Increasing the average energy production (AEP) in wind power is mainly due to the advances in integrated power electronic modules where the conduction/switching losses in high power converters/inverters have significantly reduced. As a result, the full rating inverter/converter-based wind energy conversion system using the permanent magnet synchronous generator (PMSG) has become widely-used (Muyee S. M., 2012).

A wind turbines power production capability is often presented in relation to the wind speed which is divided into four regions of operation.

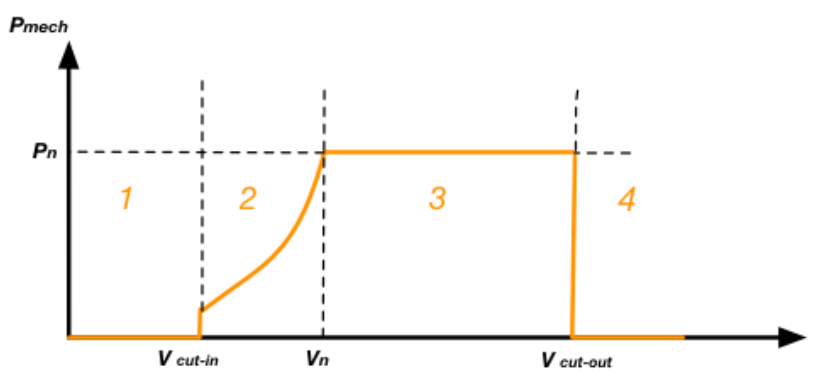

Figure 1 Ideal wind turbine power curve and the operating zones.

Region one is the startup phase where the wind speed is too low and the torque exerted by the wind is not high enough to rotate the turbine blades. Region two is where the wind accelerates to meet "cut-in speed "which is the minimum speed for the wind turbine to rotate. The pitch angle is fixed in this region to enable the blades to receive maximum pressure from the air. As the wind speed increases, the level of output power rises rapidly until it reaches the rated value of an electrical generator and its output power. The rated wind speed $\left(V_{n}\right)$ is the minimum speed that enables the wind turbine to constantly deliver its rated power. Region three is where the wind speed goes beyond the rated speed and a strong wind operating at full load.Further increase in the wind speed causes the mechanical stress on the wind turbine to reach its maximum tolerable level. Therefore, the power must be limited to protect the turbine from damaged (Zhang, X., 2013) and speed is limited to the cut-out speed. In the region four (shutting-down phase), a wind turbine is stopped from generating power.

WECS considered under this study is called a direct drive permanent magnet synchronised generator. The three-phase D-PMSG converts the mechanical power from the wind turbine into variable voltage/frequency ac electrical power, which is then converted to dc power through a PWM rectifier with a dc link allowing an optimal power extraction by the use of an MPPT algorithm. A pulse width modulation (PWM) inverter ensures the injection of produced power with constant voltage and frequency to the power grid. The main advantages of this structure are the full decoupling between two inverters, and for grid disturbance, the grid side converter is controlled to support the voltage recovery by supplying reactive power while it secures the transient grid stability (Hasnaoui O.B.K. et al., 2008).

Several control techniques suggested in the literature for maximum power point tracking (MPPT) including optimum tip speed, hill climbing and search, power signal feed-back, and artificial intelligence methods like fuzzy logic and neural networks (Thongam J. S. and Ouhrouche M., 2011). In this study, a version of optimum tip speed control is implemented to fit in our practical setup measurement and produce the maximum power tracking. The tip speed control will maximise the power produced by the wind when the wind speed is below its rated value and limit the electrical power by controlling the blades when the wind speed passes its rated value (Azar A.T. and Serrano F.E., 2015).

Controlling the stator current, the rotor speed and the Dc-link voltage are the main parameters to be controlled in the PMGS wind turbine system in this study. To control the mentioned parameters, several PI controllers are used.Proportional-Integral-Derivative (PID) control is the most common control algorithm used in industry due to their robust performance in a wide range of operating conditions and their functional simplicity (Priyadarshini D. and Rai S., 2014).

There have been numerous papers outlining the optimisation of energy production in wind turbines at an overall system level (Wang Q. and Chang L., 2004; Boukhezzar B. and Siguerdidjane H., 2009; Tamaarat A. and Benakcha A., 2014). To compliment these studies this paper focuses on the inner control loops of the generator using real machine parameters and laboratory optimised control algorithms to explore actual generator performance for a variable wind regime. The major contribution of the work in this paper can be summarised in: 
- Capture the maximum mechanical power generated by a wind turbine by using a MPPT algorithm and several PI controllers for controlling mainly the stator currents and the rotor speed to have the constant Dc-link voltage and working in the optimum range of wind speed.

- Tuning the PI controller by an experimental test at the laboratory with the practical setup.

The rest of the paper is organised as follows: in Section 2.1 and 2.2, a review of system modelling and wind turbine aerodynamics are presented, respectively. In Section 2.3 an overall description of the PI controller used in this paper is presented. In Section 2.4 and 2.5, the generator side converter (GSC) and the grid side converter (GSC) control system are explained and their Simulink block diagrams are shown and investigated.In Section 3, the simulation results are depicted and discussed. Finally, conclusion is given in Section 4.

\section{SYSTEM DESCRIPTION MODELING}

AND

\subsection{Block diagram of the proposed system}

The structure of a direct-driven PMSG Wind Turbine system is shown in Fig. 2. The control scheme of PMSG is a complete back-to-back convertor between the PMSG and power grid with an intermediate storage capacitor. This converter connects the stator winding of the synchronous generator to the grid. The Machineside converter (MSC) controls the active and reactive power output of the PMSG while the Grid-side converter (GSC) maintains the dc-link voltage constant and controlling the exchanged reactive power between the dc link and the grid, i.e., the active power extracted from the wind turbine is transferring to the grid at an adjustable power factor by the GSC. The dc chopper circuit, which consists of power electronic modules connected in series with dump resistors, is used to maintain a stable dc-link voltage during power grid faults (Wu Z. et al., 2013). The main task of the PMSM control system is to control the electromagnetic torque indirectly by the sinusoidal 3-phase stator currents required to be synchronised with the respective motor phase back emf. In this paper, sinusoidal pulse width modulation (SPWM) is used for the current control.

\subsection{Wind Turbine Aerodynamics Modeling}

In the wind energy system, mechanical energy is captured in the airflow and converted to electrical energy. Wind turbine controllers are very important for both machine operation and power production. They include sensors, controllers, power amplifiers, switches, actuators and computers/microprocessors (Manwell J.F. et al., 2010). A wind turbine must generate electricity at different wind speeds; therefore multiple control systems

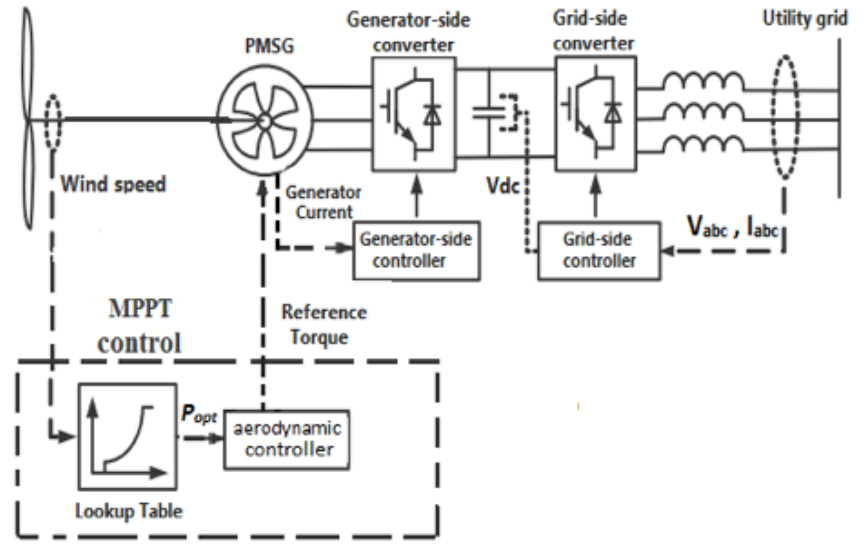

Figure 2 Block diagram of the system.

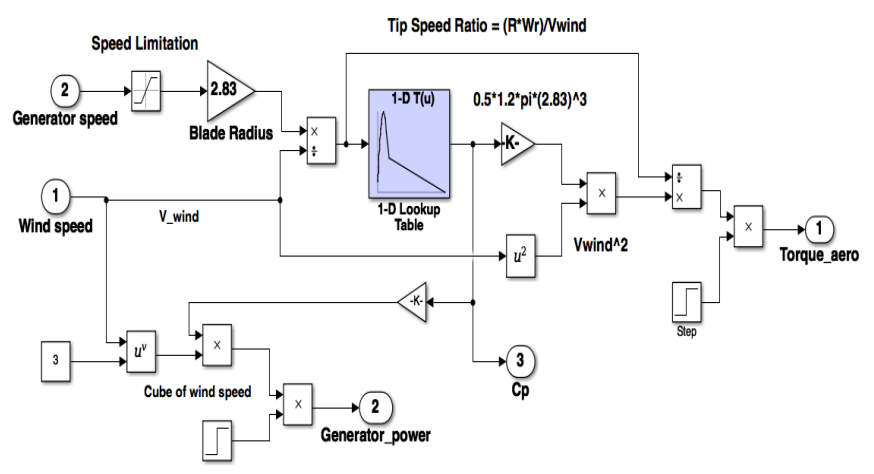

Figure 3 Wind turbine structure.

need to be implemented. To control the output power of wind turbine, there are several ways depending on the design of the wind turbine and its parameters. Torque control is chosen for this study as one of the standard control methods. The wind turbine structure for the model is shown in Fig. 3.

The applied wind speed to the blades of the turbines $(V)$ results in rotating the blades and transferring mechanical power to the shaft $\left(P_{m}\right)$. The power generated in the form of kinetic energy of the air flow depends on the size of the wind turbine and the wind speed. This mechanical power can be described by:

$$
P_{m}=0.5 \rho_{A I R} \pi R^{2} C_{P}(\lambda, \beta) V^{3} .
$$

where $\rho_{A I R}$ is the air density $\left(1.225 \mathrm{~kg} / \mathrm{m}^{3}\right), R$ is the blade radius $(m), V$ is the wind speed $(\mathrm{m} / \mathrm{s}), C_{P}$ is the power efficiency coefficient which is a nonlinear power function of tip speed ratio $\lambda$ and the blade pitch angle $\beta$; and

$$
\lambda=\frac{R \omega_{t}}{V},
$$

where $\omega_{t}$ is the rotor angular speed of the wind turbine and $R$ is the rotor blade radius. The pitch angle is the angle between the wind flow direction and the turbine blade. The pitch angle $\beta$ indicates how the wind 
velocity impacts the wind turbine blades. When $\beta=0$ the blade is fully impacted by the wind velocity, and the wind turbine will capture the maximum power in the wind. It can be shown that the theoretical static upper limit of $C_{P}$ is $16 / 27$ (approximately 0.593 ). This means we can theoretically extract circa $59.3 \%$ of the kinetic energy of the wind, which is called Betz's limit(Ackermann T. ed., 2005). The power efficiency coefficient $C_{P}$, is expressed by

$$
\begin{aligned}
& C_{P}(\lambda, \beta)=C_{1}\left(C_{2}\left(\frac{1}{\lambda+0.08 \beta}-\frac{0.035}{\beta^{3}+1}\right)-C_{3} \beta\right. \\
& \left.-C_{4}\right) e^{-C_{5}\left(\frac{1}{\lambda+0.08 \beta}-\frac{0.035}{\beta^{3}+1}\right)}+C_{6} \lambda .
\end{aligned}
$$

where $C_{1}=0.5109, C_{2}=116, C 3_{1}=0.4, C_{5}=21, C_{6}=$ 0.0068 .

In the wind turbine structure, there are three adjustable blades of length $R$ that are fixed on a drive shaft rotating at a speed of rotation $\Omega_{t}$, connected to a gain multiplier. This multiplier rotates the electric generator. Therefore, all the three blades can be modelled as a single mechanical system which is characterised by the sum of all the mechanical characteristics. In the aerodynamic design of the blades, the coefficient of friction of the blades is very small compared to that of the air and can be neglected. Similarly, the friction losses is negligible due to the very low turbine speed (Ghoudelbourk S. et al., 2016).

Assuming a constant $V$, the tip-speed ratio, $\lambda$, will vary proportionally to the rotational speed of the wind turbine rotor. If the $C_{P}(\lambda, \beta)$ curve is known for a specific fixed pitch wind turbine with a turbine rotor radius of $R$, it is easy to construct the curve of $C_{P}$ against rotational speed for any $V$. Therefore, the optimal operational point of the wind turbine at a given $V$ is determined by tracking the rotor speed to the point $\lambda_{\text {opt }}$ (Ackermann T. ed., 2005).

$$
\begin{aligned}
& \lambda_{\text {opt }}=\frac{R \cdot \omega_{t}}{V} . \\
& \omega_{t_{\text {opt }}}=\frac{\lambda_{\text {opt }} \cdot V}{R} .
\end{aligned}
$$

For every value of $V$, there is an optimum rotor speed $\omega_{t_{o p t}}$ which produces maximum power recovered from the wind turbine. The aerodynamic mechanical torque on the rotating shaft $(\mathrm{Nm})$ unit can then be calculated as:

$$
\Gamma_{m}=\frac{P_{m}}{\omega_{t}}
$$



Figure 4 Blade pitch angle.

$$
\Gamma_{m}=\frac{0.5 \rho_{A I R} \pi R^{2} C_{P}(\lambda, \beta) V^{3}}{\omega_{t}} .
$$

It is essential to maintain $\omega_{t}=\omega_{t_{o p t}}$ to maximise $P_{m}$, which is an objective of the maximum power point tracking (MPPT) control. This means $C_{P}$ has to reach its maximum value $C_{p_{\max }}$ for the maximum power to be extracted from the wind.This is implemented by controlling the electrical rotational speed of the generator rotor $\omega_{e}$, which has the following relationship with $\omega_{t}$ as:

$$
\omega_{e}=N_{p p} \omega_{m}
$$

where $N_{p p}$ is the number of pole pairs in the PMSG, and $\omega_{m}$ is the mechanical rotational speed of the generator rotor (Ackermann T. ed., 2005). This mechanical speed $\left(\omega_{m}\right)$ accelerates or decelerates with respect to the wind turbine driving the following torque equation (Yazdani A. and Iravani R., 2010):

$$
\Gamma_{e}-\Gamma_{m}=J_{e q} \frac{d \omega_{m}}{d t}
$$

where $\Gamma_{e}$ and $\Gamma_{m}$ are the electrical and the mechanical torque of the generator, respectively, and $J_{e q}$ is the total equivalent inertia of the generator (the turbine inertia plus the generator inertia).

\subsection{Proportional Integral (PI) Controller}

PI regulators have been extensively used in the renewable energy conversion systems due to their satisfactory behaviour in most of the control processes. PI regulator removes the error from the signal by implementing a control effect to the past and present cumulative value of the error (Lichtman A. and Fuchs P., 2017). Thus, $P I$ regulator removes the error from the signal by implementing a control effect to the past and present cumulative value of the error (Lichtman A. and Fuchs P., 2017). The mathematical representation of the $P I$ regulator in time domain is expressed by:

Digital pulse width modulation scheme is normally used with PI controllers to improve their satisfactory dynamic response, maintain a constant switching frequency and lower acoustic noise. Tuning of the $K_{p}$ and $K_{i}$ gains to obtain the desired control response is challenging specifically during the commissioning of a control system. The PI controller tuning methods are commonly classified into two main categories, closed loop methods and open loop methods. Tuning the controller during automatic state in which the plant is operating in closed loop is referred to closed loop tuning techniques. In contrast to close loop, when the plant operates in open loop and is in manual state is categorised as the open loop technique (Shahrokhi M. and Zomorrodi A., 2013). A comprehensive review of the different proposed methods to tune the gains of a PI regulator can be found in (Zigmund B. et al., 2006; Wang Y. G. and Shao H. H., 2000). 
In this study, in the PI controller structure, the values for $P$ and $I$ gains, sampling time and the saturation limits are obtained based on several practical experimental tests carried out at laboratory.

\subsection{Machine-Side Converter Controller Model}

Machine-side converter (MSC) controller regulates the speed of the generator to work at the maximum power point and determine the required current. It has two subsystems, one is to regulate the generator speed and the other is to control the current by PWM current control strategy. In the speed controller block (Fig. 5), the actual rotor speed of the generator is compared with a reference speed and then by using a $P I$ controller the reference current for the current controller block is determined.

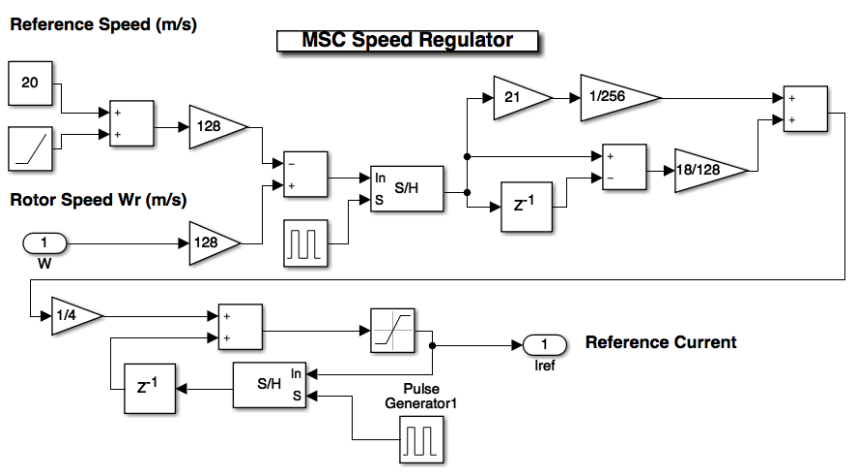

Figure 5 MSC speed regulator.

In the sinusoidal PWM current control strategy each motor phase current are compared with the sinusoidal reference current. The reference current is then introduced to a sine wave generator synchronised with the PMSG rotor position with a phase shift of $120^{\circ}$ .The control block as shown in Fig. 6 includes the current control loop with three independent PI controllers for each phase current.

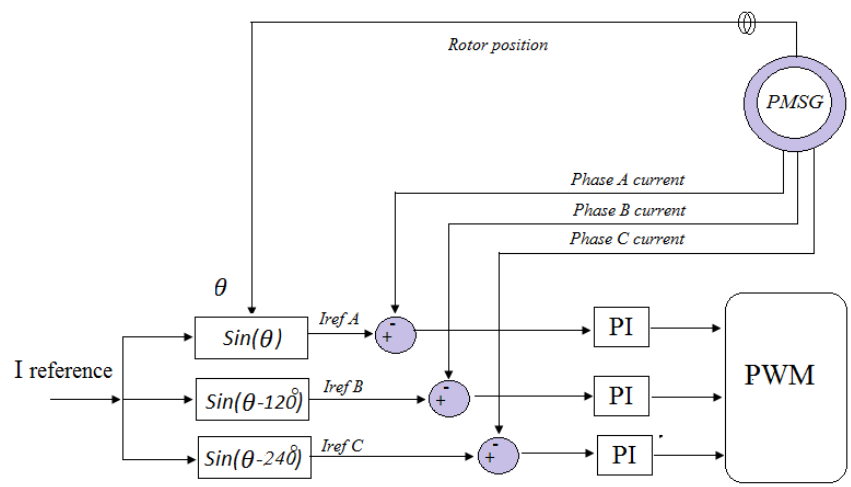

Figure 6 The sinusoidal PWM current control technique.

In the current controller block shown in Fig. 8, the rotor position works as an input for the sine wave function blocks to generate the proper current references and is subsequently decoded to create the commutation signals for the upper and lower phase gate drivers in the generator side converter. This is implemented by a sinetriangle pulse width modulation (STPWM) controller. The output signal of the PI controller is compared with a $10 \mathrm{KHz}$ triangular signal to generate the control signals for the converter switches. In the PWM system, the sinusoidal control waveform set the desired fundamental frequency of the inverter output, while the triangular waveform set the switching frequency of the inverter.

In practice, a star connected resistor network is used to observe the generator phase back electromotive force $(\mathrm{EMF})$ to which the sinusoidal phase reference waveforms are synchronised. To investigate the required mentioned phase relationship between the generator back EMF and the switch commutation control signals, a star connected resistor network with the inverter disconnected from the generator is carried out as shown in Fig. 7.

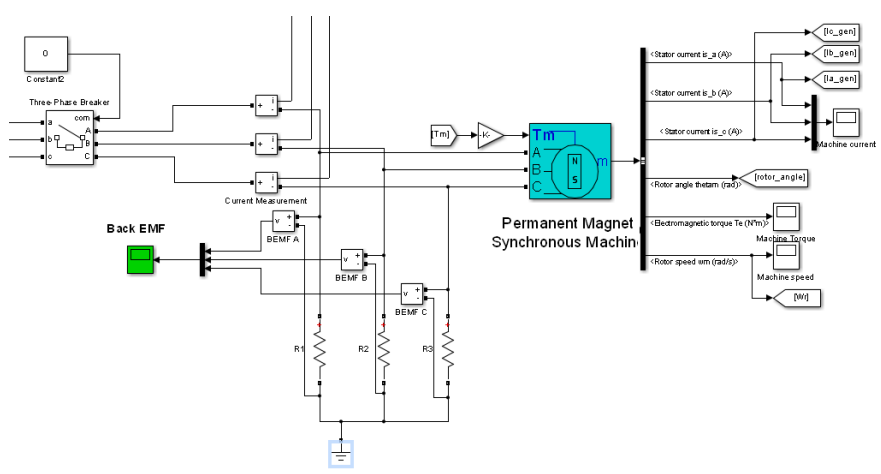

Figure 7 The generator back electromotive force (BEMF) measurement.

\subsection{Grid-Side Converter Controller Model}

Grid-side converter GSC controller is designed to maintain constant dc voltage in the dc bus and provide the required power. It composes of two controllers for current and voltage. In the grid side current regulator, the grid phase voltages determine the phase of the reference currents (the PM machine is generating).

To maintain system stability, there must be a dc link voltage controller to control the amplitude of the current injected into the grid. The dc link controller regulates the relevant voltage to a given reference level (see Fig. $10)$.

\section{SIMULATION ANALYSIS RESULT DISCUSSION}

AND

A simulation model of a PMSG-based WECS is developed in this section to validate the proposed control scheme in a practical setup. A classical method of tuning the PI regulator parameters specifically, an empirical 




Figure 8 MSC current controller.

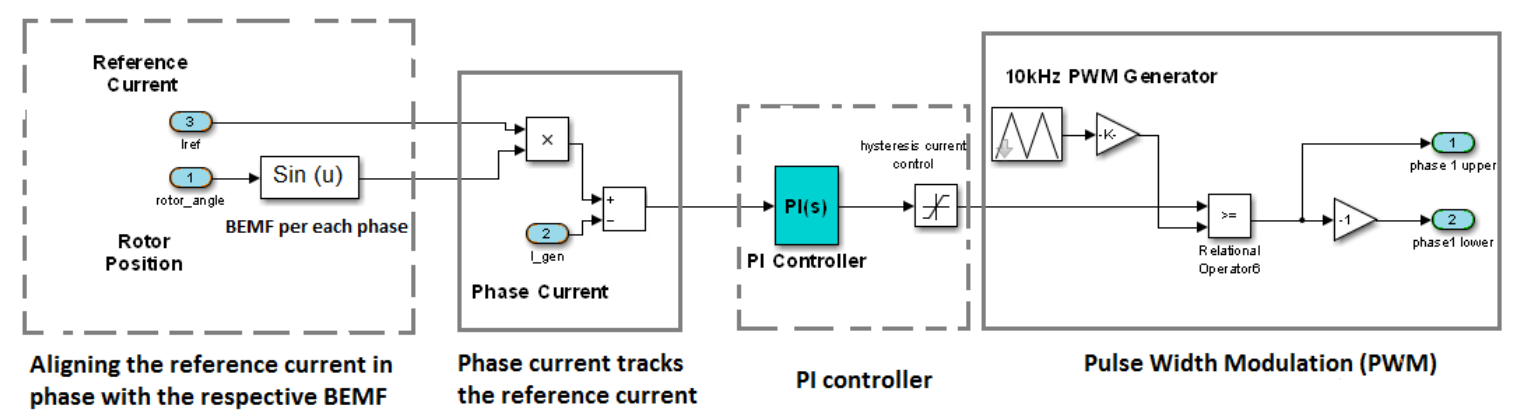

Figure 9 Current regulator structure.



Figure 10 Grid-side converter (GSC) voltage regulator.

tuning method is used. The PMSG-based wind power unit is connected to the utility grid via a two-level PWM back-to-back converter. Since dc output voltage from the converter will contain harmonics due to switching, a RL series filter is used to filter harmonics in voltage signals. To acquire the generator optimum speedThe MPPT algorithm at variable wind speed (the cut-in wind speed of $6 \mathrm{~m} / \mathrm{s}$ changing gradually to the rated wind speed $12 \mathrm{~m} / \mathrm{s}$ ) is implemented. All block system parameters are listed in the Table 1. The MSC and GSC modules are built with two-level six IGBT switches in parallel with diodes to allow bidirectional current flow and unidirectional voltage blocking capability. The wind speed profile is presented in Figures 12 .

The main component is a variable block which represents the changing wind speed of $6 \mathrm{~m} / \mathrm{s} \sim 12 \mathrm{~m} / \mathrm{s}$. The White Gaussian noise is added to the wind speed profile. The rate limiter ensures that the wind speed is not under the cut-in speed and not above the cutout speed of the turbine. To simulate the effect of the wind speed properly and provide a more realistic representation of the mechanical output of the wind turbine, the wind speed is modelled based on realistic scenarios.

As shown in Fig. 13, from the start of simulation until $0.1 s$ when reference current in generator side (step of $0.1 s$ ) starts to regulate the current, there is no current in the generator. In Fig. 14, the actual generator current tracks the reference current after a few milliseconds of simulation running time. From $0.1 s$ to the time that the dc link capacitor is charged and reaches $250 \mathrm{~V}$, which is 


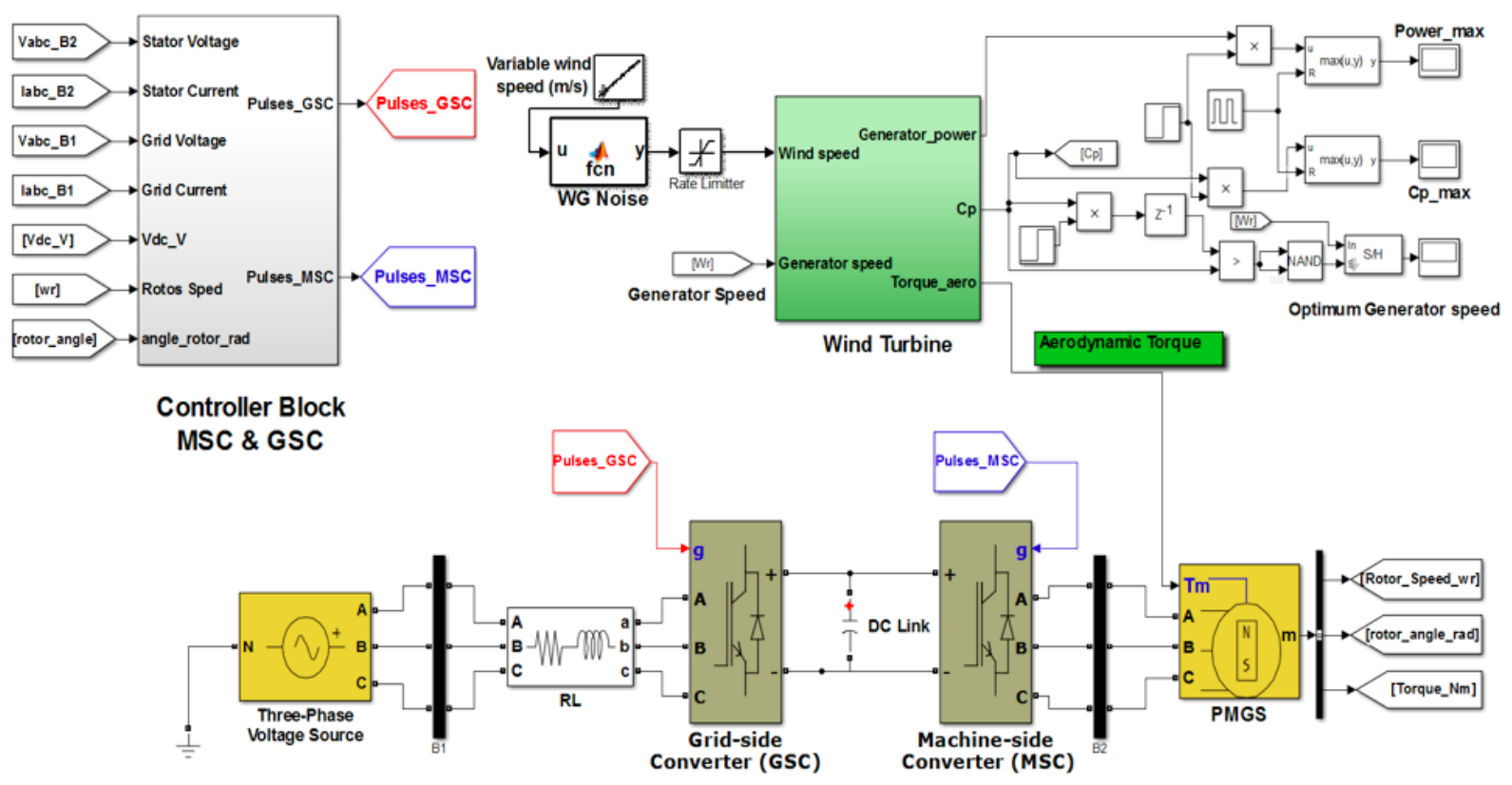

Figure 11 Permanent magnet synchronous generator based variable speed wind turbine system in MATLAB/Simulink.

Table 1 PMSG WT DRIVE PARAMETERS.

\begin{tabular}{ll}
\hline Parameter & Value \\
\hline WT Blade radius $(r)$ & $2.83 \mathrm{~m}$ \\
WT Pitch angle $(\beta)$ & $0 \circ$ \\
Maximum $W T$ power coefficient $\left(C_{p}\right)$ & 0.3643 \\
Wind speed range $(V)$ & 6 to $12 \mathrm{~m} / \mathrm{s}$ \\
Optimum tip speed ratio $(\lambda)$ & 12.3 \\
Stator resistance $\left(R_{S}\right)$ & $0.007 \Omega$ \\
Stator inductances $\left(L_{d}, L_{q}\right)$ & $0.02 \mathrm{H}$ \\
Magnetic flux linkage $\left(\psi_{r}\right)$ & $0.3 \mathrm{~Wb}$ \\
Number of poles $\left(N_{p p}\right)$ & 2 \\
Moment of inertia $(J)$ & $0.1 \mathrm{~kg} . \mathrm{m}^{2}$ \\
PMSG's Initial speed $\left(\omega_{m}\right)$ & $20 \mathrm{rad} / \mathrm{s}$ \\
PM rated power $\left(P_{m}\right)$ & $1.5 \mathrm{KW}$ \\
Rotor type & Salient pole \\
Converter's Switches $(S)$ & $\mathrm{IGBT}-\mathrm{Diod}$ \\
DC bus capacitor $(C)$ & $0.01 \mathrm{~F}$ \\
DC link voltage $\left(V_{d c}\right)$ & $250 \mathrm{~V}$ \\
Switching frequency $\left(f_{s w}\right)$ & $10 \mathrm{KHz}$ \\
Voltage of grid $\left(V_{r m s}\right.$ ph-ph) $\left(V_{a b c}\right)$ & $138 \mathrm{~V}$ \\
Frequency of grid $(f)$ & $50 \mathrm{~Hz}$ \\
Resistance in RL filter $(R)$ & $0.1 \Omega$ \\
Inductance in RL filter $(L)$ & $10 \mathrm{e} 3 \mathrm{H}$ \\
\hline
\end{tabular}

$0.89 \mathrm{~s}$, there is no current in the grid side as seen in Fig. 15. The capacitor is then discharged and the grid-side inverter is able to transfer power. It is evident from the grid current Fig. 15 that stability is achieved early to ensure the stable and efficient operation of the WECS. The dc-link capacitor is charged by the generator-side inverter. The grid voltage is 3-phase sinusoidal with the amplitude of $138 V_{r m s}$ AC source as seen in Fig. 16.

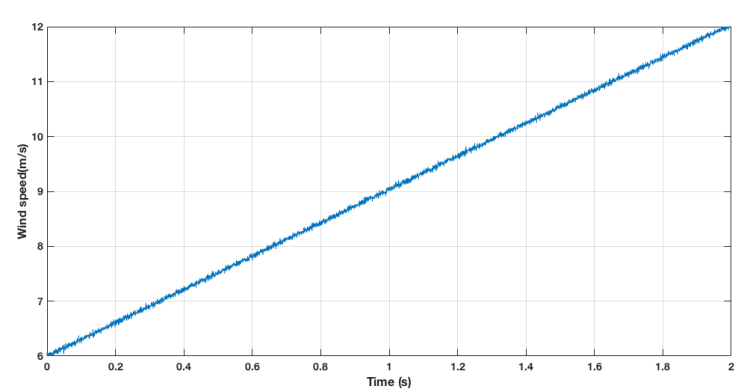

(a)

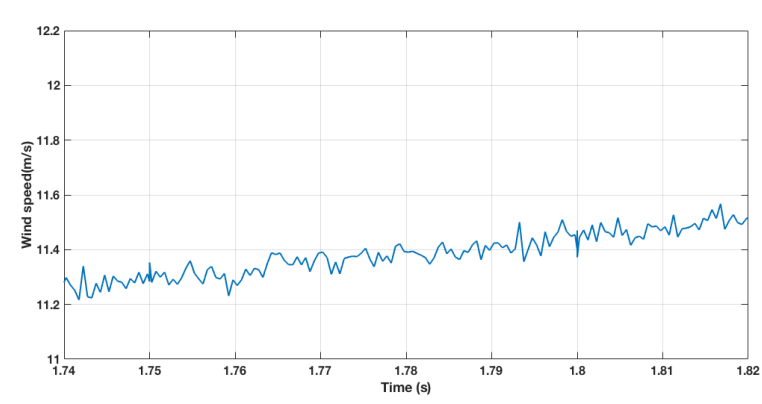

(b)

Figure 12 (a) The wind speed profile (m/s) (b) The zoom plot of the wind speed $(\mathrm{m} / \mathrm{s})$.

Fig. 13 shows that the $\mathrm{AC}$ current in the generator is maintained below a certain range due to the saturated input of the current controller, i.e. $50 \mathrm{~A}$ in this study. The generator currents (phase $a$, phase $b$ and phase c) are all sinusoidal currents and the harmonic content is observed to be minimised. Moreover, it can be seen that the amplitude of the current is changing since the 


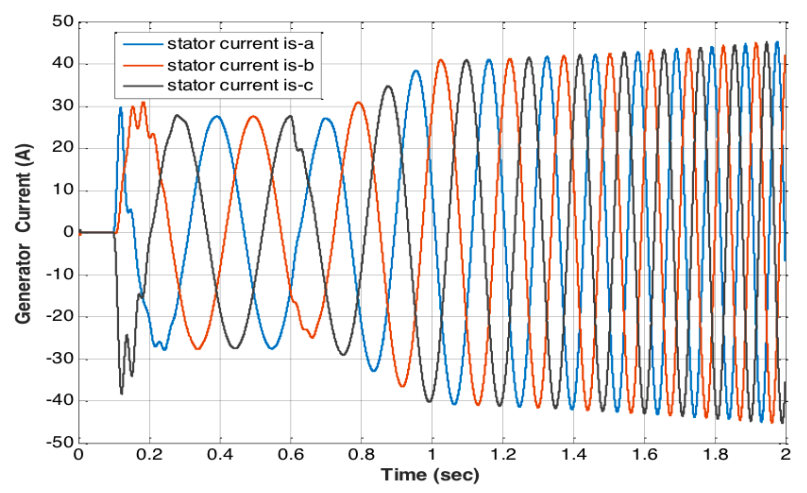

Figure 13 The generator current (A).

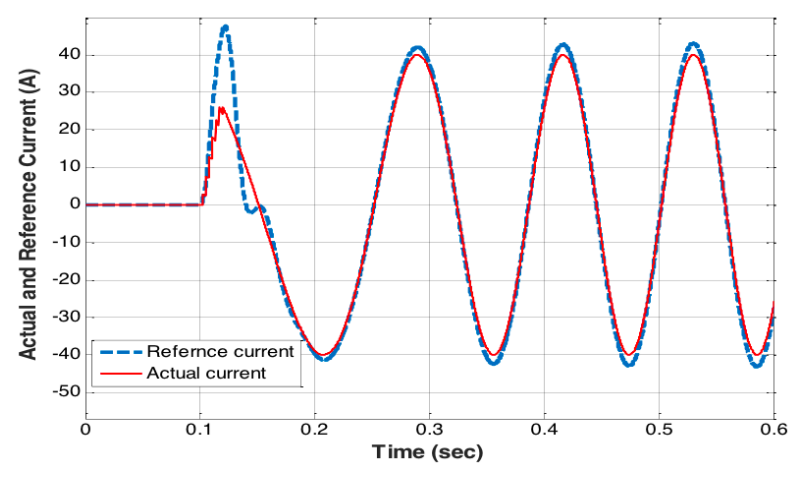

Figure 14 The actual current versus the reference current (A).

inverter controller varies the amplitude of the current output in order to control the dc bus voltage constant. In Fig. 17, the dc-link voltage is clamped to its desirable value of $250 \mathrm{~V}$ due to the activation of the threshold level in the voltage controller circuit in the grid-side controller. As a result, the dc-link voltage is remained constant and stabilised at its reference value. The electromagnetic torque of generator is also shown in Fig. 18. The generator speed remains constant at $20 \mathrm{~m} / \mathrm{s}$ until its reference value is increased to $50 \mathrm{~m} / \mathrm{s}$ after $0.6 s$ in the speed regulator. The real power obtained from the WECS using the proposed controller achieves its maximum available power which is analytically calculated based on MPPT algorithm at variable speed wind between $6 \mathrm{~m} / \mathrm{s}$ to $12 \mathrm{~m} / \mathrm{s}$, c.f. Fig. 19 .

The integrated controller can be improved by adding a pitch angle controller. When the available wind power is beyond the equipment rating, the blade pitch angle controller increases the pitch angle to limit the mechanical power delivered to the shaft and when the available wind power is less than equipment rating, the blades are set at the minimum pitch to maximise the mechanical power. Various parameters in the system are chosen to provide desirable results during the entire operating range of the turbine. At the start of the simulation, a damped oscillation can be observed in the results due to the electrical and mechanical losses. After

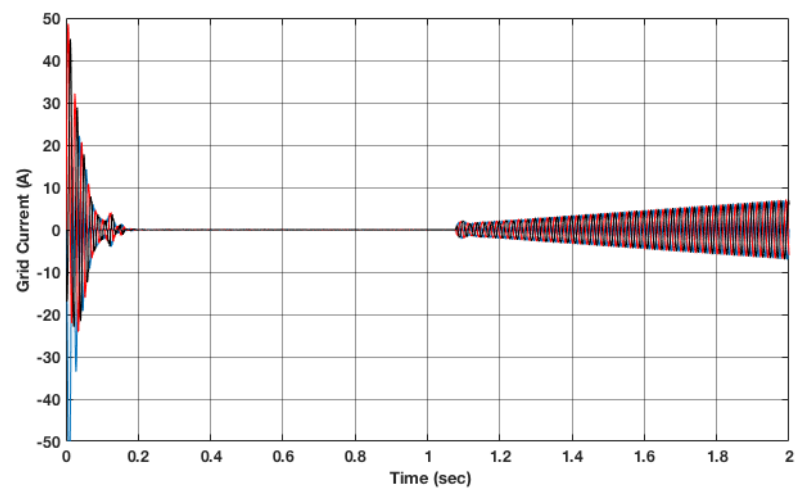

(a)

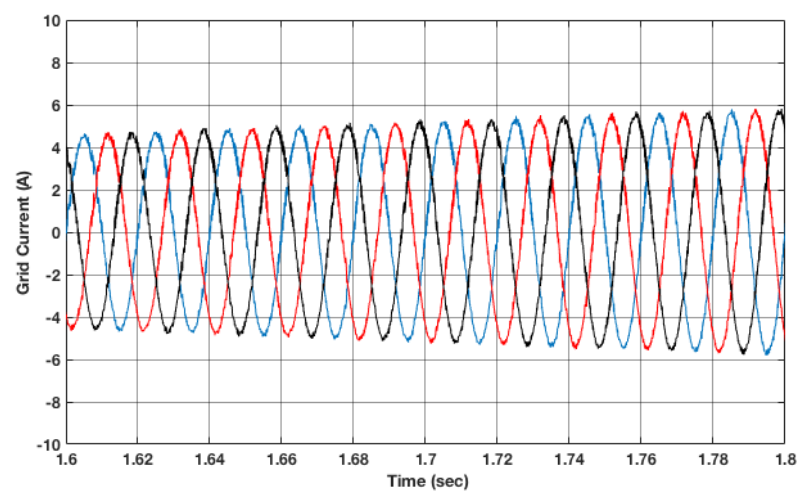

(b)

Figure 15 (a) The grid current (b) The zoom plot of the grid current (A).

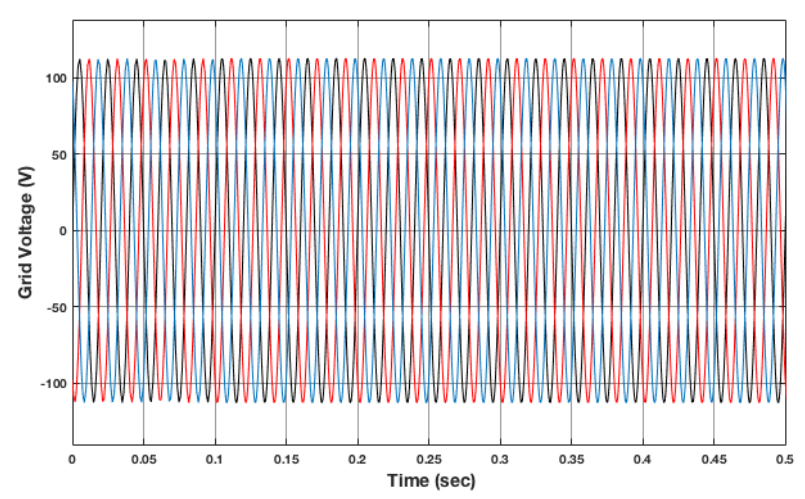

Figure 16 Grid voltage (V).

a period of acceleration, the electrical torque of the $P M$ machine and the wind torque enter a balanced state and the rotor speed accelerates as the wind speed is increasing. In the case of fixed wind speed, the rotor speed stabilised to a constant value after acceleration as evident in Fig. 21 for the fixed wind speed of $10 \mathrm{~m} / \mathrm{s}$.

We always have to consider systematic and mechanical limitations of the system. For instance, in the aerodynamic section, c.f. section 2.2 , in order to calculate the tip speed ratio (TSR) as well as the optimal TSR must be known and given to the controller, both the wind speed and turbine speed need to be also measured. The 


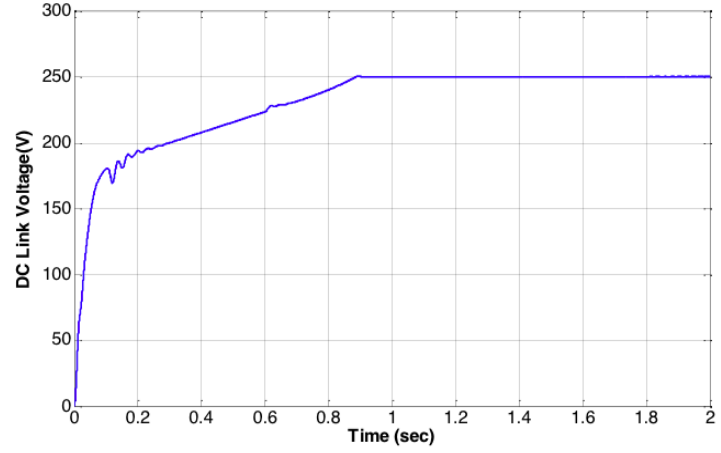

Figure 17 DC-link voltage (V).

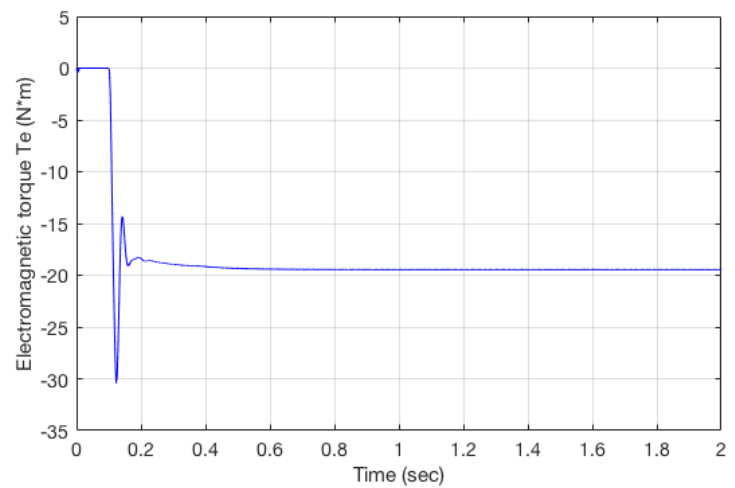

Figure 18 The Electromagnetic torque (Nm) of the generator at fixed wind speed $=10 \mathrm{~m} / \mathrm{s}$.
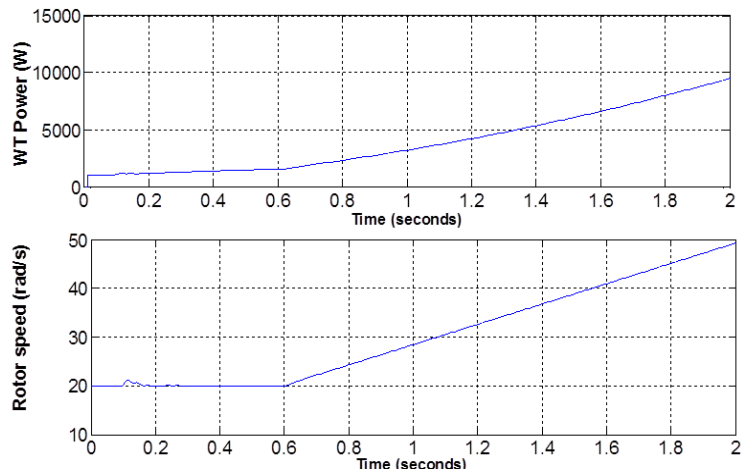

Figure 19 The generator speed $(\mathrm{rad} / \mathrm{s})$ and WT power (W) for the variable wind speed.

first challenge to implementing TSR control is measuring the wind speed that leads to difficulty in the practical implementation and the extra cost to the system. The second limitation is related to obtaining the optimal value of TSR which is not unique and dependent on the system, so it is different from one system to another. This mainly depends on the turbine/generator characteristics resulting in custom-designed control software tailored for individual wind turbines (Raju A.B. et al., 2004).



Figure 20 The power (W) captured from WT at fixed wind speed $=10 \mathrm{~m} / \mathrm{s}$.

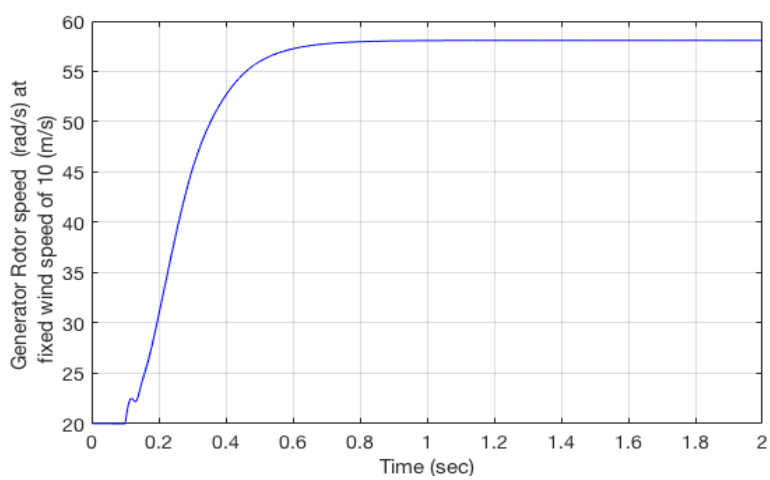

Figure 21 The generator speed $(\mathrm{rad} / \mathrm{s})$ for fixed wind speed of $10 \mathrm{~m} / \mathrm{s}$.

\section{CONCLUSION}

It is shown that our proposed practical control strategy is capable of actively controlling the power injected to the electric grid. The MPPT algorithm is capable of extracting maximum power from the air stream at different given wind speeds. The controller of the mechanical speed is used to ensure that the rotor speed adapts to the wind speed. This results in obtaining the optimum specific speed providing the optimum mechanical power despite the variations of the wind. The stator currents are perfectly tracking their given reference values by using the tuned PI controller in current regulator system. The analysis of the variable speed wind turbine with direct drive permanent magnet synchronous machine shows that the developed model is suitable for small wind energy conversion systems and the validation of the practical results.

\section{References}

Ackermann, T. ed. (2005) 'Wind power in power systems', John Wiley and Sons.

Azar, A.T. and Serrano, F.E. (2015) 'Complex System Modelling and Control through Intelligent Soft Computations, Studies, Fuzziness and Soft 
The Simulink Implementation of a MPPT technique and control system for a Variable Speed Wind Turbine PMSG11

Computing', Design and modeling of anti wind up PID controllers, Springer,Vol. 319, pp.1-44.

Boukhezzar, B. and Siguerdidjane, H. (2009) 'Nonlinear control with wind estimation of a DFIG variable speed wind turbine for power capture optimization', Energy Conversion and Management,Vol. 50, No. 4, pp.885892.

Ghoudelbourk, S., Dib, D., Omeiri, A. and Azar, A.T. (2016) 'MPPT control in wind energy conversion systems and the application of fractional control $(\mathrm{PI} \alpha)$ in pitch wind turbine', International Journal of Modelling, Identification and Control,Vol. 26, No. 2, pp.140-151.

Hasnaoui, O.B.K., Belhadj, J. , Elleuch, M. (2008) 'Direct Drive Permanent Magnet Synchronous Generator Wind Turbine investigation - Low Voltage Ride Through capability Dynamic behavior in presence of grid disturbance', JES,Vol. 4, No. 5, pp.23.

Lichtman, A. and Fuchs, P. (2017) 'Theory of PI controller and introduction to implementation for DC motor controls', IEEE conf. on Communication and Information Technologies (KIT).

Manwell, J.F., McGowan, J.G. and Rogers, A.L. (2010) 'Wind energy explained: theory, design and application', John Wiley and Sons.

Muyee, S. M. (2012) 'Wind Energy Conversion Systems: Technology and Trends', Springer-Verlag London.

PID Theory, http://www.ni.com/white-paper/3782/en/

Polinder, H., Van der Pijl, F.F., De Vilder, G.J. and Tavner, P.J. (2006) 'Comparison of direct-drive and geared generator concepts for wind turbinesg', IEEE Trans. on energy conversion, Vol. 21, No. 3, pp.725733.

Priyadarshini, D. and Rai, S. (2014) 'Design, Modelling and Simulation of a PID Controller for Buck Boost and Cuk Converter', International Journal of Science and Research (IJSR), Vol. 3, No. 5.

Raju, A.B., Fernandes, B.G. and Chatterjee, K. (2004) 'A UPF power conditioner with maximum power point tracker for grid connected variable speed wind energy conversion system', Power Electronics Systems and Applications. Proceedings, First International Conference on. IEEE, pp.107-112.

Shahrokhi, M. and Zomorrodi, A. (2013) 'Comparison of PID controller tuning methods', Department of Chemical and Petroleum Engineering Sharif University of Technology.

Tamaarat, A. and Benakcha, A. (2014) 'Performance of PI controller for control of active and reactive power in DFIG operating in a grid-connected variable speed wind energy conversion system', Frontiers in Energy,Vol. 8, No. 3, pp.371-378.

Thongam, J. S. and Ouhrouche, M. (2011) 'MPPT control methods in wind energy conversion systems', INTECH Open Access.

Wang, Q. and Chang, L. (2004) 'An intelligent maximum power extraction algorithm for inverter based variable speed wind turbine systems', IEEE Transaction Energy Conversion,Vol. 19, No. 5, pp.1242-1249.

Wu, Z., Dou, X., Chu, J. and Hu, M. (2013) 'Operation and control of a direct-driven PMSG-based wind turbine system with an auxiliary parallel grid-side converter', Energies,Vol. 6, No. 7, pp.3405-3421.

Wang, Y. G. and Shao, H. H. (2000) 'Optimal tuning for PI controller', Automatica,Vol. 36, No. 1, pp.147-152.

Yazdani, A. and Iravani, R. (2010) 'Voltage-sourced converters in power systems: modeling, control, and applications', John Wiley and Sons.

Zhang, X. (2013) 'Modeling and analysis of a novel wind turbine structure', International Journal of Modelling, Identification and Control,Vol. 19, No. 2, pp.142-149.

Zhu, Y., Cheng, M., Hua, W. and Wang, W. (2012) 'A novel maximum power point tracking control for permanent magnet direct drive wind energy conversion systems', Energies,Vol. 5, No. 5, pp.13981412 .

Zigmund, B., Terlizzi, A.A., del Toro Garcia, X., Pavlanin, R. and Salvatore, L. (2006) 'Experimental evaluation of PI tuning techniques for field oriented control of permanent magnet synchronous motors', Advances in Electrical and Electronic Engineering, Vol. 5, No. 1-2, pp.114. 